\title{
AIP
}

\section{Photopyroelectric response of PTCa/PEEK composite}

Giuliano Pierre Estevam, Washington Luiz Barros de Melo, and Walter Katsumi Sakamoto

Citation: Rev. Sci. Instrum. 82, 023903 (2011); doi: 10.1063/1.3552193

View online: http://dx.doi.org/10.1063/1.3552193

View Table of Contents: http://rsi.aip.org/resource/1/RSINAK/v82/i2

Published by the AIP Publishing LLC.

\section{Additional information on Rev. Sci. Instrum.}

Journal Homepage: http://rsi.aip.org

Journal Information: http://rsi.aip.org/about/about_the_journal

Top downloads: http://rsi.aip.org/features/most_downloaded

Information for Authors: http://rsi.aip.org/authors

\section{ADVERTISEMENT}

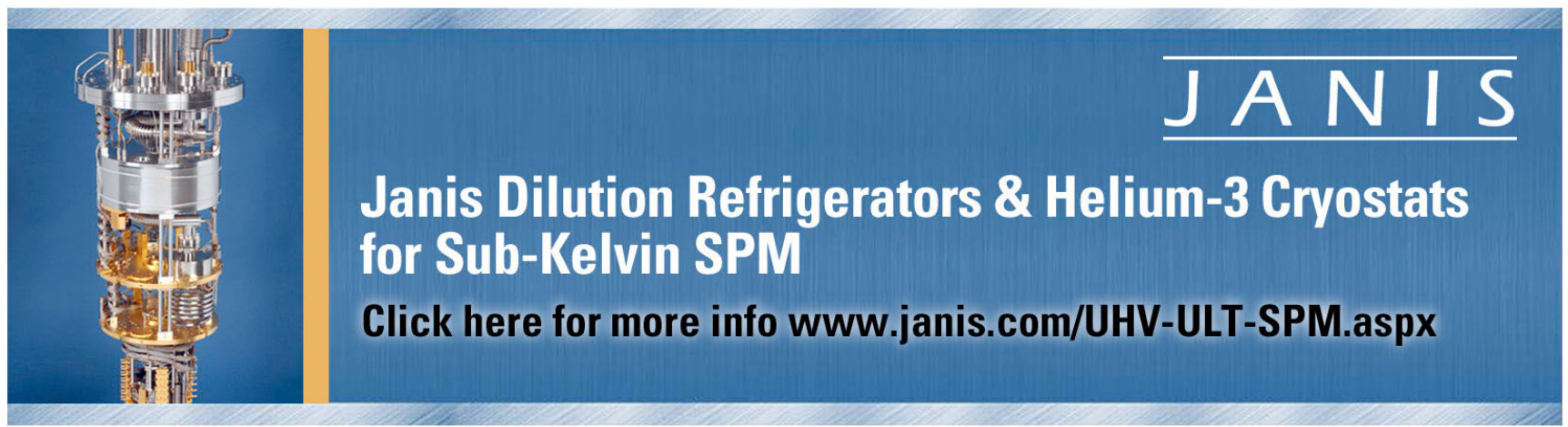




\title{
Photopyroelectric response of PTCa/PEEK composite
}

\author{
Giuliano Pierre Estevam, ${ }^{1}$ Washington Luiz Barros de Melo, ${ }^{2}$ and \\ Walter Katsumi Sakamoto ${ }^{3, a)}$ \\ ${ }^{1}$ Departamento de Engenharia Elétrica, Universidade Estadual Paulista-UNESP, Av. Brasil, 56, \\ Ilha Solteira (SP), Brazil \\ ${ }^{2}$ Empresa Brasileira de Pesquisa Agropecuária-EMBRAPA, São Carlos (SP), Brazil \\ ${ }^{3}$ Departamento de Física e Química, Grupo de Polímeros, Universidade Estadual Paulista-UNESP, \\ Av. Brasil, 56, 15385-000 Ilha Solteira (SP), Brazil
}

(Received 30 August 2010; accepted 13 January 2011; published online 17 February 2011)

\begin{abstract}
A pyroelectric composite made of calcium modified lead titanate ceramic and polyether-ether-ketone high performance polymer was obtained in the film form by hot pressing the ceramic/polymer mixture into the desired composition. After polarization with a suitable electric field, a ceramic composite film $(60 \%$ vol.) exhibited a pyroelectric figure of merit three times higher than that of a lead zirconate titanate ceramic. The material was used as infrared radiation sensor. The voltage responsivity decreases with the inverse of the frequency showing the same behavior of the thermally thick sensor. The reproducibility of the sensor responses was observed. (C) 2011 American Institute of Physics. [doi:10.1063/1.3552193]
\end{abstract}

\section{INTRODUCTION}

Composite materials made of ferroelectric ceramic immersed in nonferroelectric polymer matrix are wellestablished alternatives to conventional single crystals, ferroelectric ceramic, and ferroelectric polymer as pyroelectric detectors. Although ferroelectric ceramics have higher pyroelectric coefficient $[p(T)]$ than ceramic/polymer composite, there are advantages using the latter, such as formability, flexibility, resistance against mechanical shock, ${ }^{1-3}$ and the possibility to change the dielectric permittivity $\left(\varepsilon^{\prime}\right)$ of the composite material by changing the ceramic content. ${ }^{4,5}$ The important properties to look for in sensors are low dielectric permittivity and high pyroelectric coefficient because the ratio between these two material properties gives high voltage responsivity. The pyroelectric figure of merit (FOM) is proportional to the pyroelectric coefficient and inversely proportional to the relative dielectric permittivity $(\kappa),{ }^{6}$

$$
\mathrm{FOM}=\frac{p(T)}{\kappa} .
$$

Immersing ceramic particles into a polymer matrix to fabricate the composite material with $0-3$ connectivity, ${ }^{7}$ the dielectric permittivity can be reduced. The optimum value of FOM can be obtained by combining the pyroelectric activity provided by the ceramic content and the dielectric constant of the sample. In the present work, the calcium modified lead titanate (PTCa) ceramic was used due to its low dielectric constant $(\kappa=220)$ (Ref. 8) in comparison with the PZT ( $\kappa$ $=1200$ ) (Ref. 8) and the polymer matrix polyether-etherketone (PEEK), besides the high performance of $\kappa=3 .{ }^{9}$ Furthermore, the voltage responsivity of the composite was studied as a function of modulating frequency.

Although the FOM of PTCa ceramic is higher than that of the composite studied in this work, the formability and the

a)Electronic mail: sakamoto@dfq.feis.unesp.br. low ceramic content of the composite material makes it an interesting material to be used as an infrared detector.

\section{EXPERIMENTAL}

\section{A. Polymer matrix}

The PEEK is a high performance thermoplastic, widely used in the aerospace industry. The aromatic structure allows a higher working temperature. Its glass transition temperature is around $416 \mathrm{~K}$ and the working temperature around $673 \mathrm{~K} .{ }^{10}$

\section{B. Ferroelectric ceramic}

The PTCa is the calcium modified lead titanate, which has lower dielectric constant in comparison with the PZT. Although its piezo and pyroelectric activities are smaller than those of PZT, the relation $p / \kappa$ can be higher. Table I shows some properties of PTCa with $\left(\mathrm{Pb}_{0.76} \mathrm{Ca}_{0.24}\right)\left[\left(\mathrm{Co}_{0.5} \mathrm{~W}_{0.5}\right)_{0.05} \mathrm{Ti}_{0.95}\right] \mathrm{O}_{3}$ composition from GEC Marconi, UK.

\section{Composite}

PTCa/PEEK composite film was obtained by hot pressing the mixture of both PEEK and PTCa powder with $30 \mathrm{MPa}$ at $633 \mathrm{~K}$ for $2 \mathrm{~h}$. The films were obtained in the thickness range of 100 to $300 \mu \mathrm{m}$. The ceramic content was calculated using Eq. (2).

$$
M_{c}=M_{P} \frac{\rho_{c}}{\rho_{P}}\left(\frac{\Phi_{c}}{1-\Phi_{c}}\right),
$$

here $M$ is the mass, $\rho$ is the density, and $\Phi_{c}$ is the ceramic volume fraction. The subscript $c$ and $p$ are related to the ceramic and polymer, respectively.

To fabricate the composite film, the powders mixture was put between three layers of aluminum foil, which was put 
TABLE I. Properties of PTCa and PZT.

\begin{tabular}{lccccc}
\hline \hline Material & $\begin{array}{c}\text { Density } \\
\left(\mathrm{g} / \mathrm{cm}^{3}\right)\end{array}$ & $\begin{array}{c}\text { Dielectric } \\
\text { constant (at } 1 \mathrm{kHz})\end{array}$ & $\begin{array}{c}\text { Piezoelectric } \\
\text { coefficient }\left(\mathrm{d}_{33}\right)(\mathrm{pC} / \mathrm{N})\end{array}$ & $\begin{array}{c}\text { Pyroelectric coefficient } \\
\mathrm{p}(\mathrm{T}) \times 10^{-6} \mathrm{C}_{\mathrm{m}} \mathrm{m}^{2} \mathrm{~K} \text { RT }(\text { Ref. 8) }\end{array}$ & $\begin{array}{c}\mathrm{FOM}=(\mathrm{p} / \kappa) \times 10^{-6} \mathrm{C} / \mathrm{m}^{2} \mathrm{~K} \\
\text { at RT }(\text { Ref. 8) }\end{array}$ \\
\hline PTCa & 6.8 & 220 & 68 & 380 & 1.73 \\
PZT & 7.2 & 1200 & 190 & 420 & 0.25 \\
\hline \hline
\end{tabular}

between two steel plates. To avoid glue of the sample in the steel plates, a silicon fluid was applied between the steel plates and the layers of aluminum foil. After $2 \mathrm{~h}$ at $633 \mathrm{~K}$, the sample was cooled down to room temperature, cut in the suitable size and aluminum electrodes of $1.0 \mathrm{~cm}$ diameter were vacuum evaporated onto both sides of the sample and then the composite film was poled with a suitable electric field using a Trek model $610 \mathrm{C}$ high voltage source. To avoid breakdown, the poling process was conducted with the sample immersed in a silicone oil bath. The values used in this work were: poling field $E_{P}=12 \mathrm{MV} / \mathrm{m}$, poling temperature $T_{P}=433 \mathrm{~K}$, and poling time $t_{P}=1 \mathrm{~h}$.

\section{MEASUREMENTS}

\section{A. Pyroelectric coefficient $p(T)$}

Pyroelectric is the change in the polarization due to a temperature change. Hence, the pyroelectric coefficient is determined by the polarization charge variation $(d Q)$ because of the changing temperature $(d T)$. Equation (3) provides the values of $p$ as a function of temperature,

$$
p(T)=\frac{1}{A} \frac{d Q}{d T},
$$

where $A$ is the sample's electrode area.

In the direct method ${ }^{11}$ of measuring $p(T)$, the poled sample is heated with a constant rate $\left(1^{\circ} \mathrm{C} / \mathrm{min}\right)$ with its electrodes short circuited. The depolarization current is monitored with an electrometer and stored in a microcomputer. The temperature is also stored. The heating cycle was from room temperature to $393 \mathrm{~K}$, lower than the poling temperature.

The current obtained in the first and second cycles can contain a contribution of irreversible current due to impurities or charge injection during the polarization. The amplitude of the current goes down as the contributions to the irreversible current are released. When there is no appreciable change in the current amplitude, the pyroelectric current is established, only due to the polarization. Hence, Eq. (3) can be rewritten as

$$
p(T)=\frac{1}{A} \frac{I_{p}}{d T / d t},
$$

where $I_{p}$ is the reversible pyroelectric current and $d T / d t$ is the heating rate.

\section{B. Dielectric spectroscopy}

The dielectric behavior of the composite film was studied by measuring the permittivity $\left(\varepsilon^{\prime}\right)$ and the dielectric loss $\left(\varepsilon^{\prime \prime}\right)$ at room temperature, in the frequency range of $1.0-10^{3} \mathrm{kHz}$. An impedance analyzer HP model 4192 was used and Eqs. (5) and (6) provide the values of $\varepsilon^{\prime}$ and $\varepsilon^{\prime \prime}$, respectively, ${ }^{12}$

$$
\begin{gathered}
\varepsilon^{\prime}=\frac{L Y^{\prime}}{A \omega \varepsilon_{o}} \\
\varepsilon^{\prime \prime}=\frac{L Y^{\prime}}{A \omega \varepsilon_{o}}
\end{gathered}
$$

where $Y^{\prime}$ and $Y^{\prime \prime}$ are the real and imaginary parts of the complex admittance, respectively, $\omega$ is the angular frequency, $A$ is the electroded area of the sample, and $\varepsilon_{\mathrm{o}}$ is the vacuum permittivity.

\section{Responsivity}

When the detector is exposed to a modulated radiation it generates an electrical signal, which is called responsivity $\left(R_{v}\right) \cdot{ }^{13,14}$ Equation (7) shows the relation between the responsivity and the power of the incident radiation,

$$
R_{v}=\frac{V_{o}}{I_{w}}=\frac{p(T) \eta}{c \varepsilon_{o} \kappa A v},
$$

where $V_{o}$ is the output voltage, $I_{w}$ is the input power of the incident radiation, $\eta$ is the absorbed fraction of the radiation, $p(T)$ is the pyroelectric coefficient, $c$ is the specific heat, $\kappa$ is the relative permittivity, $v$ is the modulation frequency $(\mathrm{Hz})$, and $A$ is the electrode area.

\section{Photopyroelectricity}

The upper face of the composite sample, which is painted with black ink to optimize the energy absorption, absorbs the modulated incident radiation. Since the composite film is a thermal transducer and the absorbed energy increases the temperature of the sample, the heat is transformed into an electrical signal generated by the potential difference between the two faces of the sample.

The variation of photopyroelectric voltage $(\Delta V)$ depends on the temperature variation $(\Delta T)$ and can be written ${ }^{15,16}$,

$$
\Delta V=\frac{p(T)}{\varepsilon_{o} \kappa} L \Delta T,
$$

where $L$ is the sample thickness. According to Mandelis and $\mathrm{Zver}^{16}$ for the optically opaque and thermally thick pyroelectric sample, i.e., as $L_{s}>\mu_{s}=\left(2 \alpha_{s} / \omega\right)^{1 / 2}\left(\mu_{s}\right.$ being the thermal diffusion length), Eq. (8) can be rewritten as

$$
V(\omega)=\frac{A_{0}}{\omega} \exp \left[-\left(\frac{\omega}{2 \alpha_{s}}\right)^{1 / 2} L_{s}-i \varphi\right]
$$




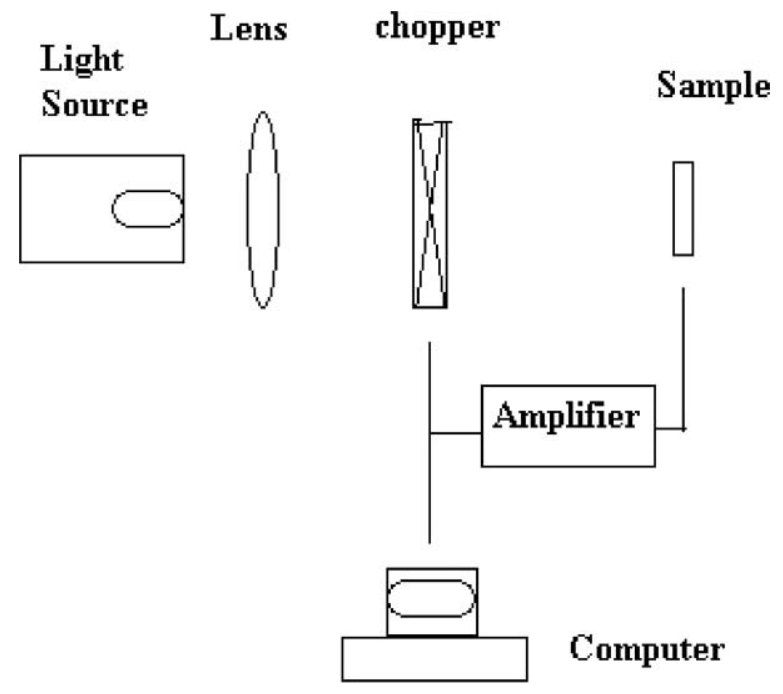

FIG. 1. Block diagram of the photopyroelectric measure system.

where $A_{0}=\left(p / \varepsilon_{0} \kappa\right) \eta I_{0} F$ is the amplitude, $\eta$ is quantum efficiency, $I_{0}$ is the light intensity, $F$ is the thermal coefficient, which depends on the thermal parameters of the sample, $\omega$ is the angular frequency of light modulation, $\alpha_{s}$ is the thermal diffusivity of the sample, $L_{s}$ is its thickness, and $\varphi$ is the phase of the photopyroelectric signal.

Figure 1 shows the block diagram of the photopyroelectric measuring system. A light beam from a $250 \mathrm{~W}$ halogen lamp (Oriel) is focused on the sample after being chopped (Chopper Oriel 75152). A Lock-In amplifier (SR530) measures the voltage from the sample.

\section{RESULTS AND DISCUSSION}

Figure 2 shows the behavior of the pyroelectric coefficient $p(T)$ as a function of temperature. The measurements were carried out in the temperature range of $273-300 \mathrm{~K}$ for samples with 40,50, and 60 vol. \% of ceramic. All samples were poled with suitable electric field of $12 \mathrm{MV} / \mathrm{m}$ for $1 \mathrm{~h}$ at $433 \mathrm{~K}$.

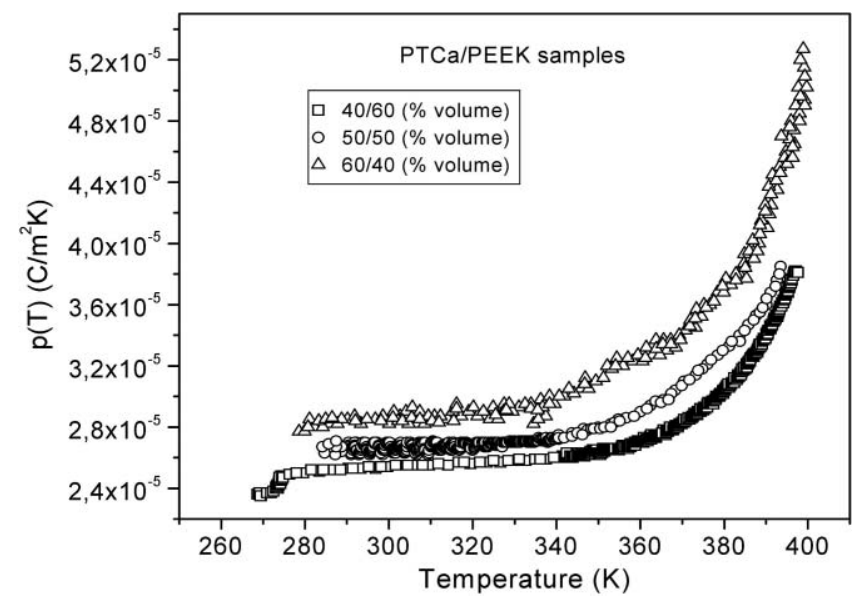

FIG. 2. Behavior of pyroelectric coefficient. Samples poled at 433 K. $E_{P}$ $=12 \mathrm{MV} / \mathrm{m}$.

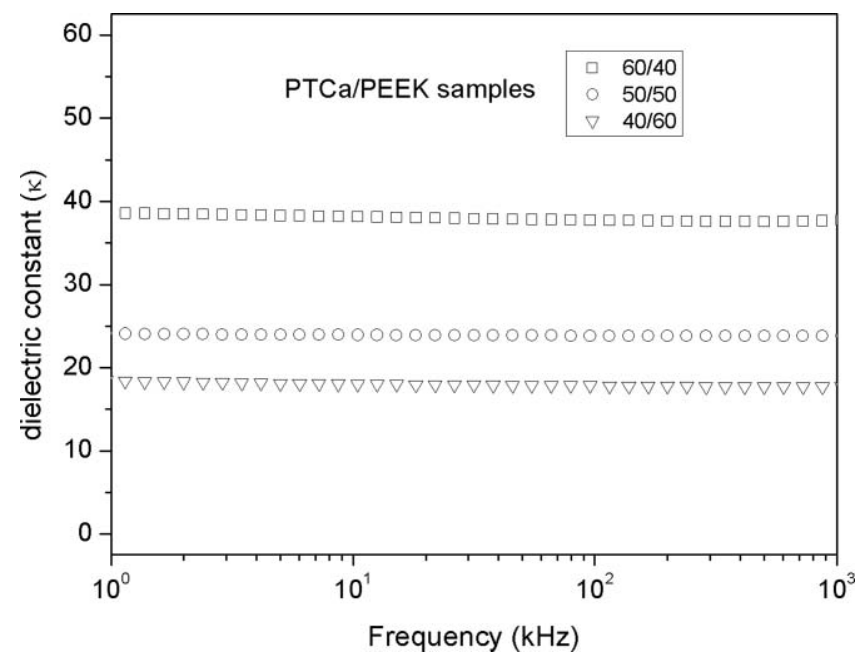

FIG. 3. Dielectric constant of PTCa/PEEK composite films at room temperature.

The values of $p(T)$ were obtained using Eq. (3) on the pyroelectric current established after the third run of the thermally stimulated discharge current measurement. A change in the intensity of the discharge current was observed during the first and second runs due to the release of an electrical charge injected during the poling process or due to impurities in the sample. As the pyroelectric activity is due to the ceramic phase, the samples with 60 vol. \% of ceramic exhibited a higher pyroelectric coefficient. Although the pyroelectric coefficient will be higher with increasing ceramic content, over 60 vol. \% of ceramic the composite film becomes brittle and also the connectivity is no longer just $0-3$, becoming a mixed connectivity.

Figure 3 shows the behavior of the dielectric constant $\kappa$ in the frequency range of $1-10^{3} \mathrm{kHz}$. Higher is the ceramic volume fraction, greater is the constant $\kappa$. At $1 \mathrm{kHz}$ the value of the dielectric constant for the PTCa ceramic is 230, while for PEEK polymer it is 3.2. For the composite film with 60 vol. \% the value of $\kappa$ is 38.4 and using the same method reported by several researchers, the pyroelectric FOM obtained was three times higher than those of PZT, although the pyroelectric coefficient is much lower. For comparison, the FOM values for PZT and for the composite PZT/PVDF are shown in Table II.

Photopyroelectric measurements were performed on the three samples with different PTCa volume contents. The center of the face of the samples was painted black to maximize the light absorption. The black-ink layer is considered thermally thin in the frequency range used; therefore, there is a very low heat loss. Figure 4 shows the responsivity of three composites with different thermal properties and

TABLE II. Values of dielectric constant, pyroelectric coefficient, and FOM.

\begin{tabular}{lccc}
\hline \hline Material & $\kappa(1 \mathrm{kHz})$ & $\mathrm{p}\left(\mu \mathrm{C} / \mathrm{m}^{2} .{ }^{\circ} \mathrm{C}\right) \mathrm{RT}$ & $\mathrm{p} / \kappa$ \\
\hline PTCa/PEEK 60 vol. \% & 38.4 & 30 & 0.78 \\
PZT (Ref. 8) & 1700 & 420 & 0.25 \\
PZT/PVDF 50 vol. \% (Ref. 8) & 90 & 10 & 0.11 \\
\hline \hline
\end{tabular}




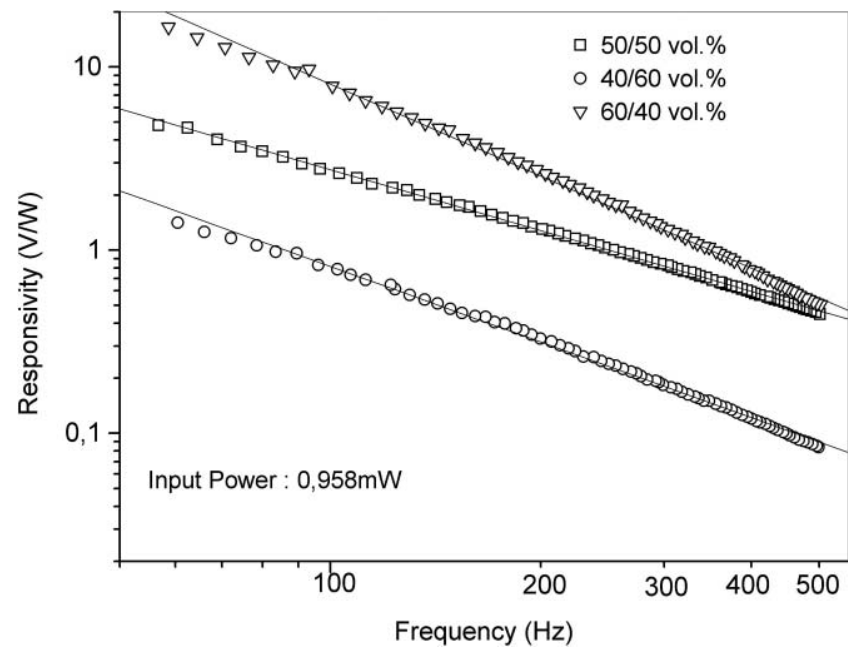

FIG. 4. Voltage responsivity as a function of light modulation frequency.

different thicknesses. The continuum lines are the linear fitting. The deviation from the linearity in the high frequency region is clear. However, the composite with 50 vol. \% of ceramic shows better linearity when compared to the other one. This behavior can be attributed to the thermal difference and also because this sample has a lower thickness (40/60 vol. \% $180 \mu \mathrm{m}$; 50/50 vol. \% $120 \mu \mathrm{m} ; 60 / 40$ vol. \% $230 \mu \mathrm{m}$ ) when compared to the other two. This is a thermally more thin material than the others in the frequency range used.

Figure 5 shows the measured output voltage as a function of the modulation frequency for different input incident white light power applied to PTCa/PEEK 60/40 vol.\% sample and the incident power was calculated using Eq. (10),

$$
I_{w}=I_{o} A
$$

being $I_{o}$ is $0.958 \mathrm{~mW}$ and $A$ is the area of the slit placed in front of the sensor chamber.

Converting the amplitude of Eq. (9), the responsivity $R$ can be obtained and

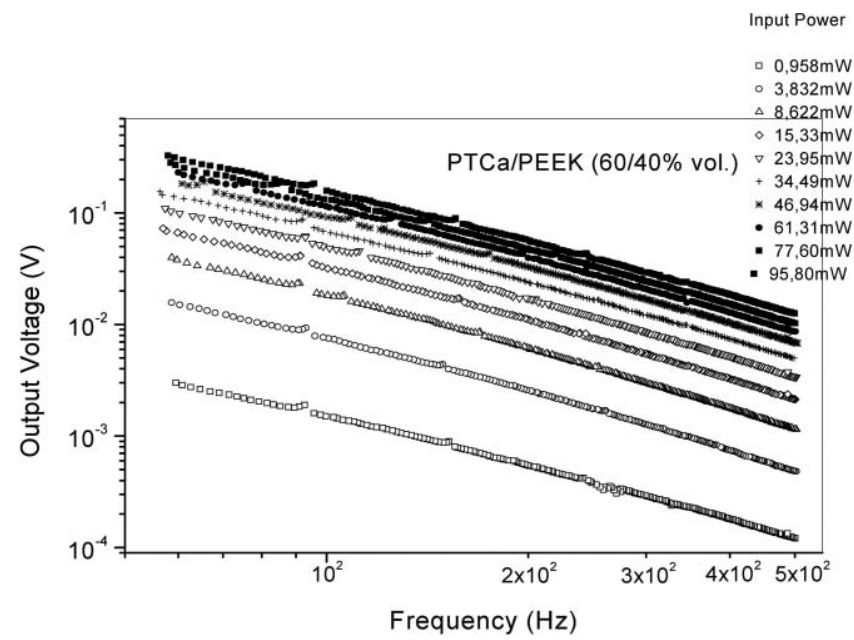

FIG. 5. Output-voltage of the sensor as a function modulation frequency for different input power.

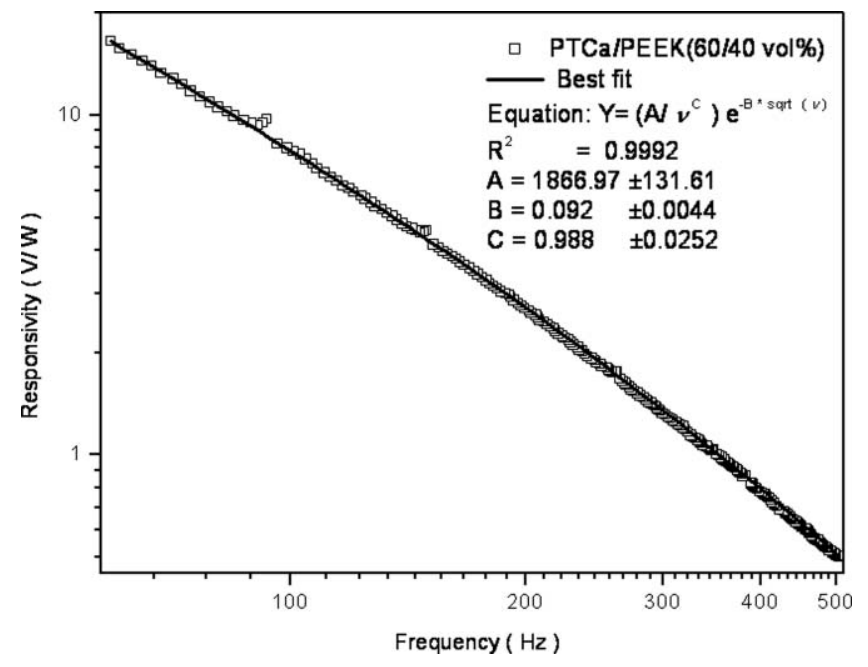

FIG. 6. Responsivity vs modulation frequency.

$$
R=\frac{A_{1}}{v} \exp \left[-\left(\frac{\pi v}{\alpha_{s}}\right)^{1 / 2} L_{s}\right]
$$

where $A_{1}$ is the amplitude, $\alpha_{s}$ is the thermal diffusivity, and $L_{s}$ is the thickness of the sample.

A log-log plot of Eq. (11) shows that the low-frequency range is controlled by the term $1 / v$ but as the frequency increases, the exponential factor becomes relevant and the signal decreases quickly. In high frequency the exponential factor domains the signal that rapidly decreases, the responsivity will depend linearly on $\log (1 / v)$. Therefore, any deviation of the linearity in the high frequency range is due to the exponential factor. The responsivity as a function of frequency in a $\log -\log$ plot is shown in Fig. 6. A good fitting is seen in the experimental data with the equation giving the value of $\mathrm{R}^{2}$ close to unity. This fitting is an indicative that the sensor behaves as predicted by the model proposed by Mandelis et al.

Using the data plotted in Fig. 5 and taking a fixed frequency, the increasing photopyroelectric signal as the input power increases is observed. However, after a certain value of input power there is no significant change in the sensor response. This may be due to the saturation of the induced dipoles response to the input light power. This is an indication that the photopyroelectric signal becomes independent of high power intensity, although this effect is not predicted in Eq. (9). This sensor does not behave linearly as a function of the input light power and of the frequency.

For a close analysis of this effect, the photopyroelectric response at different fixed frequencies was plotted against the input power. Figure 7 shows the behavior of the sensor in the input power range for all frequencies analyzed. The fitting was obtained using Eq. (12) and is represented by continuous lines in Fig. 7 ,

$$
y(W)=A_{1}\left[1-\exp \left(-\frac{W}{W_{0}}\right)\right],
$$

where $A_{1}$ is the maximum amplitude when $W>>W_{0}$ and $W_{0}$ is the exponential decay factor. 


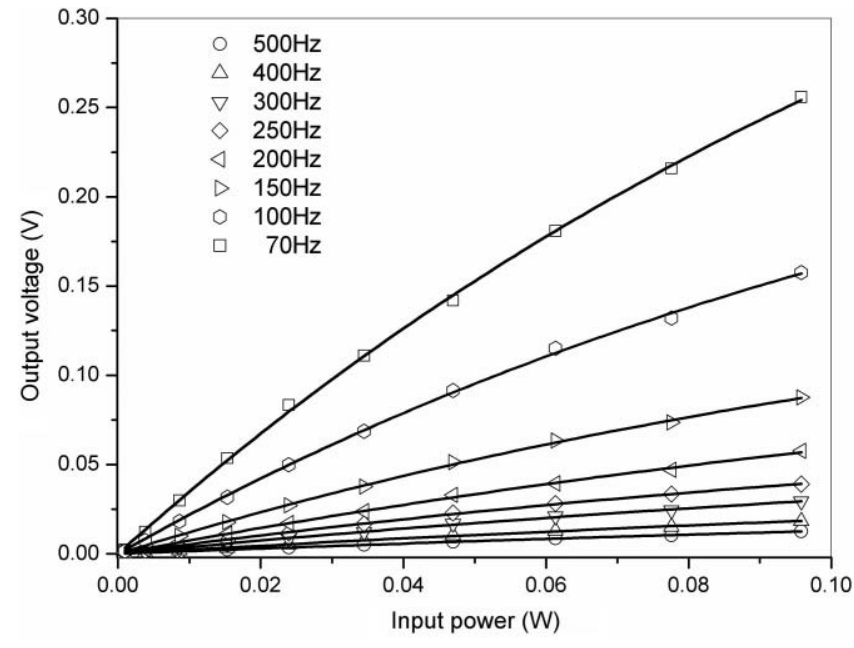

FIG. 7. Output-voltage vs input power for different fixed frequency.

Figure 8 shows the values of $\mathrm{A}_{1}$ as a function of modulation frequency. The solid line is the best curve fit of this data by a hyperbolic function. It can be observed that parameter $A_{1}$ decreases hyperbolically as the frequency increases. Yet, the sensor is influenced by a thermally thick condition for a frequency above $200 \mathrm{~Hz}\left(L_{s}>\mu_{s}\right)$. Thus, the linear behavior is evidenced in the low frequency range and low power.

Figure 9 shows the behavior of the decay factor, $W_{0}$, described in Eq. (12). A quadratic dependence with the modulation frequency is observed. A second order polynomial function was used for the best fit and it is clearly observed that over $120 \mathrm{~Hz}$ the sensor is practically linear but with poor response, i.e., if high power is applied to the sensor then its response is a low output voltage. The saturation of output voltage, $A_{1}$, will occur at a very high input power when the modulated frequency is high. In a low frequency, the sensor reaches the saturation voltage very early with a better response. The sensor can be used to detect low light intensity and heat in a modulated low frequency.

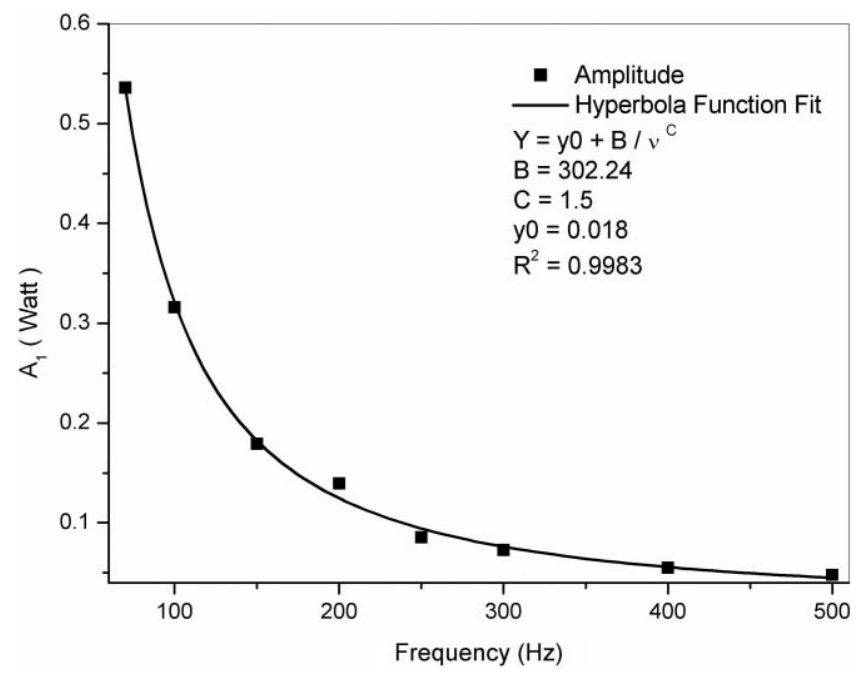

FIG. 8. Amplitude as a function of modulation frequency.

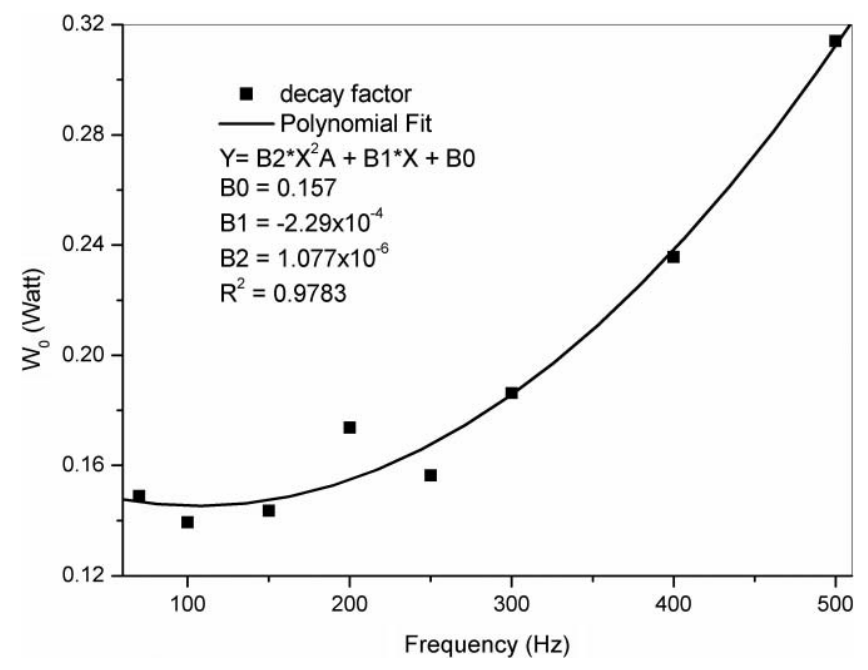

FIG. 9. Decay factor vs light modulation frequency.

Applying the fitting functions, shown in Figs. 8 and 9 in Eq. (12), we can obtain a transfer function in the low frequency and low input power of this sensor,

$$
Y(W, v)=\frac{1925.1}{v^{1.5}} W
$$

This way the sensor responds linearly with the input light power as desired.

\section{CONCLUSIONS}

A pyroelectric composite film was obtained by mixing a high performance polymer matrix and a low relative dielectric permittivity ferroelectric ceramic, hot pressing both powders into a desired volume percent for each material. After suitable polarization, the composite shows displays pyroelectric activity comparable with other polymer/ceramic composites reported in the literature. The advantage of PTCa/PEEK composite is the polymer matrix's high performance, which has a working temperature of about $673 \mathrm{~K}$ that allows high poling temperatures. Furthermore, the figure of merit is three times higher than the PZT ceramic.

As expected the sensor response increases with the increasing ceramic content and the responsivity varies with the inverse of the modulated frequency, according to the theoretical prediction [Eqs. (7) and (11)] showing the same behavior of the thermal thick sensor. In addition, the output signal increases with the input power until $61.31 \mathrm{~mW}$, when there is evidence of saturation.

\section{ACKNOWLEDGMENTS}

The authors gratefully acknowledge the Fundação de Amparo à Pesquisa do Estado de São Paulo -(FAPESP) for financial support.

${ }^{1}$ D. K. Das-Gupta and M. J. Abdullah, Ferroelectrics 87, 213 (1988).

${ }^{2}$ D. A. Van Der Ende, P. De Almeida, and S. Van der Zwaag, J. Mater. Sci. 42, 6417 (2007). 
${ }^{3}$ V. S. Nisa, S. Rajesh, K. P. Murali, V. Priyadarsini, S. N. Potty, and R. Ratheesh, Compos. Sci. Technol. 68(1), 106 (2008).

${ }^{4}$ K. W. Kwok, S. T. Lau, C. K. Wong, and F. G. Shin, J. Phys. D: Appl. Phys. 40, 6818 (2007).

${ }^{5}$ B. Ploss, Y. W. Wong, and F. G. Shin, Ferroelectrics 325, 165 (2005).

${ }^{6}$ W. K. Sakamoto, S. Kagesawa, D. H. Kanda, and D. K. Das-Gupta, J. Mater. Sci. 33, 3325 (1998).

${ }^{7}$ R. E. Newnham, D. P. Skinner, and L. E. Cross, Mater. Res. Bull. 13, 525 (1978).

${ }^{8}$ D. K. Das-Gupta, Mater. Eng. 10(2), 97 (1999).

${ }^{9}$ W. K. Sakamoto, Eclética Quim. 28(2), 49 (2003).
${ }^{10}$ Provisional data sheet PK1, "Grades, properties and processing characteristics," (Imperial Chemical Industries (ICI), UK, 1980).

${ }^{11}$ R. L. Byer and C. B. Roundy, Ferroelectrics 3, 333 (1972).

${ }^{12}$ W. K. Sakamoto, D. H. F. Kanda, and D. K. Das-Gupta, Mater. Res. Innovations. 5, 257 (2002).

${ }^{13}$ H. Schopf, W. Ruppel, and P. Würfel, Ferroelectrics 118, 297 (1991).

${ }^{14}$ M. C. Kao, H. Z. Chen, S. L. Yang, Y. C. Chen, P. T. Hsieh, and C. C. Yu, Thin Solid Films 516, 5518 (2008).

${ }^{15}$ L. Capinen, L. Masotti, V. Ferrari, D. Marioli, A. Taroni, and M. Mazzoni, Rev. Sci. Instrum. 75(1), 4906 (2004).

${ }^{16}$ A. Mandelis and M. M. Zver, J. Appl. Phys. 57(9), 4421 (1985). 